$10-2018$

\title{
Outcome of decompressive craniectomy in traumatic closed head injury
}

\author{
Altaf Ali Laghari \\ Aga Khan University, altaf.alilaghari@aku.edu \\ Muhammad Ehsan Bari \\ Aga Khan University, ehsan.bari@aku.edu \\ Muhammad Waqas \\ Aga Khan University, muhammad.waqas@aku.edu \\ Syed Ijlal Ahmed \\ Aga Khan University \\ Karim Rizwan Nathani \\ Aga Khan University
}

See next page for additional authors

Follow this and additional works at: https://ecommons.aku.edu/pakistan_fhs_mc_surg_neurosurg

Part of the Neurology Commons, Neurosurgery Commons, and the Surgery Commons

\section{Recommended Citation}

Laghari, A., Bari, M., Waqas, M., Ahmed, S. I., Nathani, K. R., Moazzam, W. (2018). Outcome of decompressive craniectomy in traumatic closed head injury. Asian Journal of Neurosurgery, 13(4), 1053-1056.

Available at: https://ecommons.aku.edu/pakistan_fhs_mc_surg_neurosurg/166 


\section{Authors}

Altaf Ali Laghari, Muhammad Ehsan Bari, Muhammad Waqas, Syed Ijlal Ahmed, Karim Rizwan Nathani, and Wardah Moazzam

This article is available at eCommons@AKU: https://ecommons.aku.edu/pakistan_fhs_mc_surg_neurosurg/166 


\section{Asizn Journalof Asian Journal of Neurosurgery \\ Home \\ Current issue Instructions Submit article}

Asian J Neurosurg. 2018 Oct-Dec; 13(4): 1053-1056.

PMCID: PMC6208257

doi: 10.4103/ajns.AJNS_195_17: 10.4103/ajns.AJNS_195_17

PMID: $\underline{30459866}$

\section{Outcome of Decompressive Craniectomy in Traumatic Closed Head Injury}

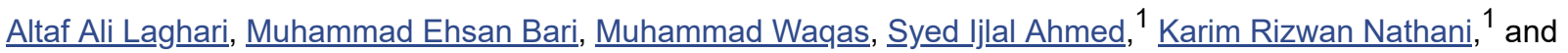
Wardah Moazzam $^{1}$

Section of Neurosurgery, Aga Khan University Hospital, Karachi, Pakistan

${ }^{1}$ Department of neurosurgery, The Aga Khan University Hospital, Karachi, Pakistan

Address for correspondence: Dr. Altaf Ali Laghari, Section of Neurosurgery, The Aga Khan University Hospital, Stadium Road, PO Box 3500, Karachi, Pakistan. E-mail: altaf.alilaghari@aku.edu

Copyright : @ 2018 Asian Journal of Neurosurgery

This is an open access journal, and articles are distributed under the terms of the Creative Commons AttributionNonCommercial-ShareAlike 4.0 License, which allows others to remix, tweak, and build upon the work noncommercially, as long as appropriate credit is given and the new creations are licensed under the identical terms.

\section{Abstract}

\section{Objective:}

The aim of the current study was to observe functional outcomes of patients undergoing decompressive craniectomy (DC) for raised intracranial pressure (ICP) after blunt head injury and to assess possible predictive factors.

\section{Methodology:}

This study was a prospective cohort study which was conducted at Aga Khan University Hospital, Karachi over a period of 2 years (January 2015-December 2016). Adult patients, aged between 15 and 65 years of both genders undergoing DC during the study period were selected. Outcomes of DC were assessed at an interval of 3 months following injury using the Glasgow outcome score. The data were analyzed on IBM statistics SPSS version 21.

\section{Results:}

Seventy-two patients underwent DC for raised and refractory ICP. Glasgow Outcome Scale (GOS) at discharge, 1-month and 3-month follow-up were reported. GOS at 3-month follow-up showed 21 patients (29.2\%) patients had a good recovery, moderate disability was reported in 16 patients $(22.2 \%)$, and severe disability in 12 patients $(16.7 \%)$, persistent vegetative state was seen in five patients (6.9\%). Eighteen patients had in hospital mortality $(25.0 \%)$. Tracheostomy and sphenoid fractures were found to be negative predictors of good functional outcome.

\section{Conclusions:}


DC is associated with an in hospital mortality of $25.0 \%$. Favorable outcomes were seen in $51.4 \%$ patients. Tracheostomy and sphenoid fractures were negative predictors of good functional outcome. The results are comparable to international literature.

Keywords: Decompressive craniectomy, intracranial pressure, Traumatic head injury

\section{Introduction}

Morbidity and mortality of patients with severe traumatic brain injury (TBI) is high. Approximately $60 \%$ either die or survive with severe disability. Raised intracranial pressure (ICP) does not respond to medical management, mannitol and hyperventilation in $10 \%-15 \%$ of patients with severe TBI.[1] Surgical decompressive craniectomy (DC) is recommended in such cases, intervention being aimed at lowering ICP to minimize secondary brain damage. $[\underline{2}, \underline{3}]$

DC has been used to treat severe intracranial hypertension secondary to various causes.[4] This involves removal of a part of the calvarium, with or without duraplasty to create extra volume for intracranial contents thereby reducing ICP.[]ㅡ DC may improve oxygen delivery to brain cells by improving blood flow.[6] It is still unclear that DC improves functional outcome in patients with severe TBI and refractory raised ICP.[7] In a recent study, 25\% of patients had good functional outcome.[]] Gupta in his study analyzed 15 studies with the total number of 129 patients and showed reduction in mortality of $25 \%-30 \%$. [9]

Several studies on DC have reported high occurrence of poor functional outcomes.[10] There is paucity of data from the developing countries, where unfavorable functional outcomes after DC can have much larger financial and social impact. The objective of this study was to observe functional outcomes patients undergoing DC for raised ICP after blunt trauma to head and to assess possible predictive factors.

\section{Methodology}

This was prospective cohort study, conducted over a period of 2 years (2015-2016) at the Department of Neurosurgery, the Aga Khan University Hospital, Karachi (AKUH). We included all patients undergoing DC after closed head injury due to blunt trauma. Patients operated outside AKUH were excluded from the study.

This study was approved by research evaluation unit, College of Physicians and Surgeon Pakistan. Informed consent was taken from all the participants at the time of inclusion in the study. Participants Information regarding demography, trauma history, clinical status, and radiographic findings were collected through predesigned pro forma.

\section{Procedure}

A standard procedure recommended in international literature was employed. In brief, in the operating room under general anesthesia, incisions were given as required (bicoronal for bilateral or frontotemporal trauma flap for unilateral) and scalp flap was raised. After making burr holes, craniotome was used to raise a bone flap, which was removed and stored in refrigerator. The dura was incised (durotomy) and then augmented using temporal fascia, pericranial fascia, or artificial fascia (duroplasty). Patients were ventilated for 24-48 h. All the patients were followed by principal investigator himself at both hospitals and at clinics after discharge for outcome. Good functional outcome was assessed using Glasgow outcome score (GOS). Data were analyzed using IBM Statistical Package for the Social Sciences (SPSS) version 21 (IBM corporation, Armonk, New castle, New York, United states of America). Categorical variables such as sex, preoperative GCS, preoperative pupil response to light, good functional outcome were analyzed using frequencies and percentages. Whereas continuous variables like age, time interval from incident to arrival and arrival to surgery were summarized using means \pm standard deviation. Inferential analysis was done for age, mode of injury, time from injury to arrival in the emergency room, arrival to DC, 
preoperative GCS, and preoperative pupillary response to light. Chi-square test was used to compare the outcomes in different strata. Binary logistic regression was also done to calculate the predictability of independent variables on the dependent variable. $P<0.05$ was considered statistically significant.

\section{Results}

A total of 72 blunt trauma patients presenting with closed head injury at AKUH, Karachi, were enrolled in this study. Average age of patients was $26.0 \pm 20.50$ years. Sixty-two $(85.9 \%)$ were males and $10(14.1 \%)$ were females.

The mean postoperative stay of the patients in the hospital was $14.93 \pm 10.55$ days. The mean GCS was $7.26 \pm 3.83$. The GOS at discharge showed mortality in 18 patients $(25 \%)$, vegetative state in 5 patients (6.9\%), severely disables in 14 patients $(19.4 \%)$, moderately disabled in 14 patients $(19.4 \%)$, and good recovery in 21 patients $(29.2 \%)$.

The mean GOS at 1-month follow-up showed no further mortality. One patient improved GOS form severely disabled to moderately disabled.

Glasgow Outcome Scale (GOS) at 3-month follow-up is shown in Figure 1. The GOS at different period of follow-up is compared below in Table 1.

Thirty-one percentage were anisocoric. Majority of patients (59.2\%) were injured by RTA, followed by fall $(22.5 \%)$ and assault (18.3\%). Tracheostomy was done in 32 (44.4\%) patients.

Extradural hematoma was present in $25.7 \%$ of the patients while subdural was present in $55.7 \%$ of patients. Subarachnoid hemorrhage and contusions were present in $32.4 \%$ and $16.2 \%$, respectively.

Facial fractures were found in $16.2 \%$, parietal fractures in 30.9\% temporal fractures among $34.3 \%$, occipital fractures in $17.9 \%$. Sphenoid fractures were present in $17.9 \%$.

Significant association was found between tracheostomy and good functional outcome $(P=0.017)$ and between sphenoid fractures and good functional outcome $(P=0.030)$. Both sphenoid fractures and tracheostomy were negatively associated with good functional outcome.

The binary logistic model was also performed to ascertain the effects of tracheostomy and sphenoid fractures on the likelihood of good functional outcome in patients with DC. The model was statistically significant $(P<0.05)$. The model explained $25.5 \%$ variance and correctly classified $55 \%$ of the cases. Tracheostomy 4.9 times and sphenoid fractures 6.7 times likely to reduce good functional outcome.

\section{Discussion}

In this study, we evaluated the outcome of DC in 72 consecutive patients with traumatic head injury. DC was effective in reducing the ICP, and it was also associated with good functional outcomes in term of good recovery and moderate disability, in survivors. As a developing country, we do not have the facility of ICP monitoring to objectively document the reduction in postoperative ICP. Decompressive craniectomy in diffuse traumatic brain injury (DECRA) investigators reported results from a multicentered, randomized clinical trial comparing DC and standard care in the management of diffuse severe TBI.[7] The results suggested that though DC lowers refractory ICP, therapeutic intensity levels and intensive care unit days, it does not improve mortality and may even worsen functional outcome at 6 months in patients with diffuse severe TBI. However, DECRA was for diffuse injury patients while most of our patients had an intracranial hematoma as well.

A study by Jagannathan et al. reported similar outcomes.[11] It was a retrospective review of prospectively acquired data of children who underwent DC at the authors' institution between January 1995 and April 2006. Although the mortality rate for children with severe TBI remains high, DC was effective in reducing 
ICP and is associated with good outcomes. Another study revealed that DC was associated with a better than expected functional outcome in patients with medically uncontrollable ICP and brain herniation, compared with outcome in other control cohorts reported on in the literature.[]]

We observed better outcomes in younger patients. GCS score of 8 and above is associated with favorable outcome, while mortality rates and the incidence of residual disabilities are much higher in patients with admission GCS of 5 and below, which is comparable to other studies.[12, $\underline{13}, \underline{14}]$ Other factors that have been associated with poor outcome include polytrauma and significant pupillary abnormalities (anisocoria or mydriasis). However, only GCS had statistically significant association. Despite the fact that ICP monitoring was not performed in any of our patients our results are comparable to other studies from west, where ICP monitoring is considered a standard of care. This supports the idea that adequate monitoring of clinical parameters is equally valuable in the management of head injury. $[\underline{15}, \underline{16}, \underline{17}, \underline{18}, \underline{19}]$ Few other studies from our institute have evaluated Rotterdam score and optic nerve sheath diameter as predictors of functional outcomes and mortality in patients undergoing decompressive craniectomy.[20,21] Both are noninvasive methods of measuring ICP. Optic nerve sheath diameter was found to have no relationship with functional outcomes or mortality in patients undergoing DC. On the other hand, Rotterdam score of computed tomography scan for TBI had a significant correlation with unfavorable outcomes and mortality of TBI patients.[20] These parameters were not studied in the current study as they are not part of the current guidelines or recommendations on the management of TBI. Another aspect of DC patients is cranial reconstruction in the form of cranioplasty. We recently presented our data on cranioplasties in children and found no relationship of the timing of cranioplasty and complication rate and cosmetic outcomes of these patients.[22] The complication rate of cranioplasty should be considered along with the complications of DC when counseling families and decision making.

Few limitations of the study were observed. There was no comparison group, and the sample size was relatively small. The study, therefore, cannot be generalized to all patients with severe brain injury. A very important drawback of DC is the increased risk of brain injury. These patients are also at high risk of repeat injury due to lack of protection as reported by Honybul.[려]

Additional multicenter Randomized Control Trials (RCTs) are necessary to provide more evidence and further conclusions on the efficacy of this DC procedure.[르, $\underline{25}, \underline{26}]$

\section{Conclusions}

DC is associated with favorable outcomes in $51.4 \%$ patients. It has in hospital mortality of $25 \%$, with tracheostomy and sphenoid fractures being negative predictors of good functional outcome. The results are comparable to international literature.

\section{Financial support and sponsorship}

Nil.

\section{Conflicts of interest}

There are no conflicts of interest.

\section{References}

1. Marshall LF. Head injury: Recent past, present, and future. Neurosurgery. 2000;47:546-61. [PubMed: 10981741]

2. Brown DA, Wijdicks EF. Decompressive craniectomy in acute brain injury. Handb Clin Neurol. 2017;140:299-318. [PubMed: 28187804] 
3. Adams H, Kolias AG, Hutchinson PJ. The role of surgical intervention in traumatic brain injury. Neurosurg Clin N Am. 2016;27:519-28. [PubMed: 27637401]

4. Kamal Alam B, Bukhari AS, Assad S, Muhammad Siddique P, Ghazanfar H, Niaz MJ, et al. Functional outcome after decompressive craniectomy in patients with dominant or non-dominant malignant middle cerebral infarcts. Cureus. 2017;9:e997. [PMCID: PMC5338989] [PubMed: 28286721]

5. Coplin WM, Cullen NK, Policherla PN, Vinas FC, Wilseck JM, Zafonte RD, et al. Safety and feasibility of craniectomy with duraplasty as the initial surgical intervention for severe traumatic brain injury. $\mathrm{J}$ Trauma. 2001;50:1050-9. [PubMed: 11426120]

6. Jaeger M, Soehle M, Meixensberger J. Effects of decompressive craniectomy on brain tissue oxygen in patients with intracranial hypertension. J Neurol Neurosurg Psychiatry. 2003;74:513-5.

[PMCID: PMC1738358] [PubMed: 12640077]

7. Cooper DJ, Rosenfeld JV, Murray L, Arabi YM, Davies AR, D’Urso P, et al. Decompressive craniectomy in diffuse traumatic brain injury. N Engl J Med. 2011;364:1493-502. [PubMed: 21434843]

8. Syed AB, Ahmad IH, Hussain M, Al-Bya F, Solaiman A. Outcome following decompressive craniectomy in severe head injury: Rashid Hospital experience. Pan Arab J Neurosurg. 2009;1:29-35.

9. Gupta R, Connolly ES, Mayer S, Elkind MS. Hemicraniectomy for massive middle cerebral artery territory infarction: A systematic review. Stroke. 2004;35:539-43. [PubMed: 14707232]

10. Honeybul S, Ho KM, Gillett GR. Reconsidering the role of decompressive craniectomy for neurological emergencies. J Crit Care. 2017;39:185-9. [PubMed: 28285834]

11. Jagannathan J, Okonkwo DO, Dumont AS, Ahmed H, Bahari A, Prevedello DM, et al. Outcome following decompressive craniectomy in children with severe traumatic brain injury: A 10-year singlecenter experience with long-term follow up. J Neurosurg. 2007;106:268-75. [PubMed: 17465359]

12. Veen EV, Aerdts S, Brink WV. Decompressive (hemi) craniectomy for refractory intracranial hypertension after traumatic brain injury. Crit Care. 2006;10:1.

13. Stiver SI. Complications of decompressive craniectomy for traumatic brain injury. Neurosurg Focus. 2009;26:E7. [PubMed: 19485720]

14. Georgiadis D, Schwarz S, Aschoff A, Schwab S. Hemicraniectomy and moderate hypothermia in patients with severe ischemic stroke. Stroke. 2002;33:1584-8. [PubMed: 12052995]

15. Phan K, Moore JM, Griessenauer C, Dmytriw AA, Scherman DB, Sheik-Ali S, et al. Craniotomy versus decompressive craniectomy for acute subdural hematoma: Systematic review and meta-analysis. World Neurosurg. 2017;101:677-8500. [PubMed: 28315797]

16. Picetti E, Caspani ML, Iaccarino C, Pastorello G, Salsi P, Viaroli E, et al. Intracranial pressure monitoring after primary decompressive craniectomy in traumatic brain injury: A clinical study. Acta Neurochir (Wien) 2017;159:615-22. [PubMed: 28236181]

17. Chesnut RM. Craniectomy for traumatic intracranial hypertension. N Engl J Med. 2016;375:2403. [PubMed: 28032968]

18. Hayman EG, Kurland DB, Grunwald Z, Urday S, Sheth KN, Simard JM, et al. Decompressive craniectomy in neurocritical care. Semin Neurol. 2016;36:508-19. [PubMed: 27907955]

19. Grindlinger GA, Skavdahl DH, Ecker RD, Sanborn MR. Decompressive craniectomy for severe traumatic brain injury: Clinical study, literature review and meta-analysis. Springerplus. 2016;5:1605. [PMCID: PMC5028365] [PubMed: 27652178] 
20. Waqas M, Shamim MS, Enam SF, Qadeer M, Bakhshi SK, Patoli I, et al. Predicting outcomes of decompressive craniectomy: Use of rotterdam computed tomography classification and marshall classification. Br J Neurosurg. 2016;30:258-63. [PubMed: 26828246]

21. Waqas M, Bakhshi SK, Shamim MS, Anwar S. Radiological prognostication in patients with head trauma requiring decompressive craniectomy: Analysis of optic nerve sheath diameter and rotterdam CT scoring system. J Neuroradiol. 2016;43:25-30. [PubMed: 26492980]

22. Waqas M, Ujjan B, Hadi YB, Najmuddin F, Laghari AA, Khalid S, et al. Cranioplasty after craniectomy in a pediatric population: Single-center experience from a developing country. Pediatr Neurosurg. 2017;52:77-9. [PubMed: 27926912]

23. Honeybul S. Decompressive craniectomy: A new complication. J Clin Neurosci. 2009;16:727-9. [PubMed: 19261473]

24. Huang HW, Zhang GB, Zhou JX. Would decompressive craniectomy really bring the hope to severe traumatic brain injury? J Thorac Dis. 2016;8:E1505-E1507. [PMCID: PMC5179403] [PubMed: 28066644]

25. Stein DM, Feather CB, Napolitano LM. Traumatic brain injury advances. Crit Care Clin. 2017;33:1-3. [PubMed: 27894490]

26. Jinadasa S, Boone MD. Controversies in the management of traumatic brain injury. Anesthesiol Clin. 2016;34:557-75. [PubMed: 27521198]

Figures and Tables 
Figure 1

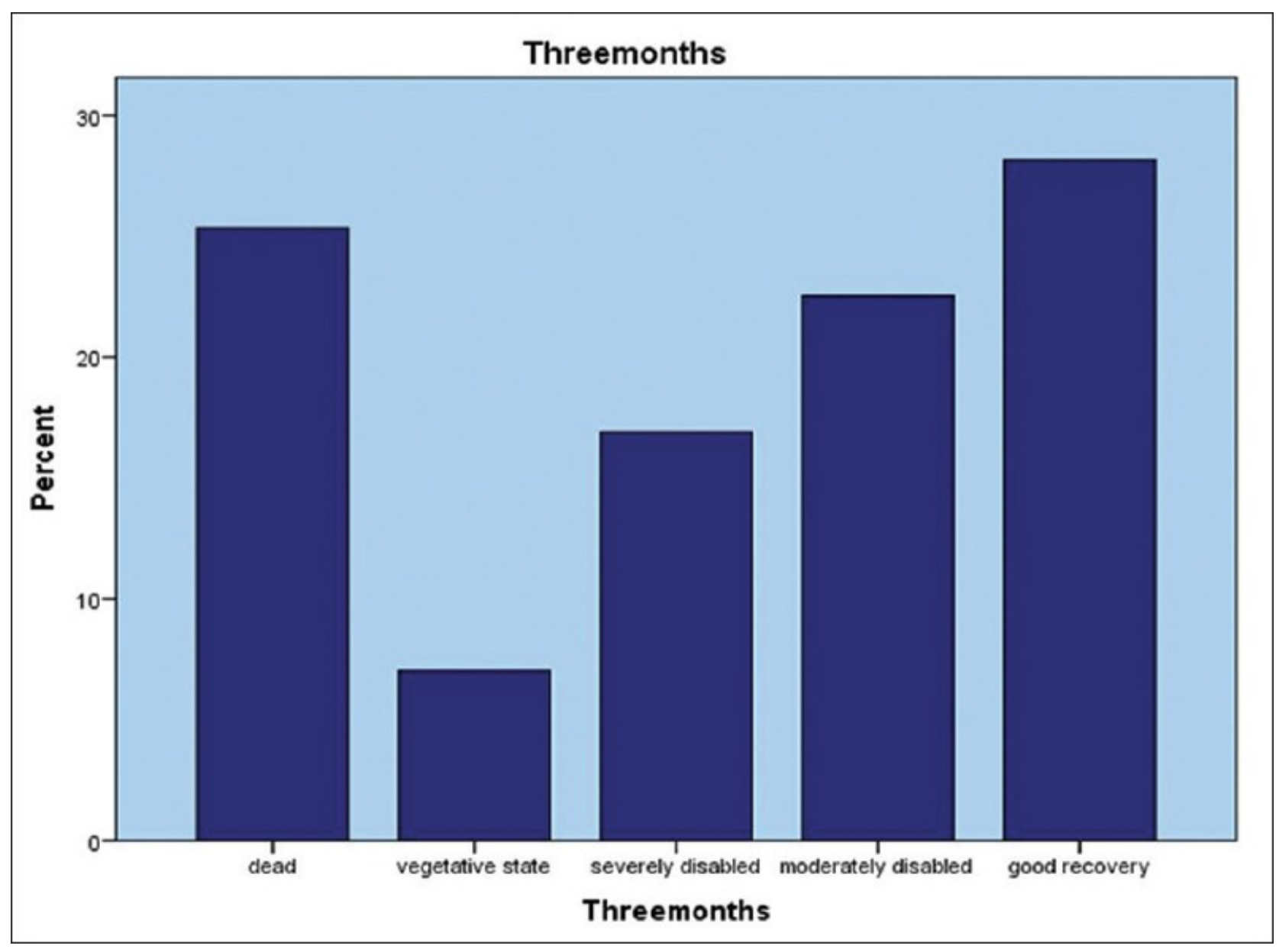

Open in a separate window

Glasgow Outcome Scale at 3 months' follow-up 


\section{Table 1}

Comparison of GCOS at different periods of follow-up

\begin{tabular}{lc}
\hline & Frequency (\%) \\
\hline At discharge & \\
Dead & $18(25.0)$ \\
Vegetative state & $5(6.9)$ \\
Severely disabled & $14(19.4)$ \\
Moderately disabled & $14(19.4)$ \\
Good recovery & $21(29.2)$ \\
Total & $72(100.0)$ \\
At 1 month & \\
Dead & $18(25.0)$ \\
Vegetative state & $5(6.9)$ \\
Severely disabled & $13(18.1)$ \\
Moderately disabled & $15(20.8)$ \\
Good recovery & $21(29.2)$ \\
Total & $72(100.0)$ \\
At 3 months & \\
Dead & $18(25.0)$ \\
Vegetative state & $5(6.9)$ \\
Severely disabled & $12(16.7)$ \\
Moderately disabled & $16(22.2)$ \\
Good recovery & $21(29.2)$ \\
Total & $72(100.0)$ \\
\hline OS: Glassgow outcome score
\end{tabular}

GOS: Glassgow outcome score

Open in a separate window

Articles from Asian Journal of Neurosurgery are provided here courtesy of Wolters Kluwer -- Medknow Publications 